\title{
Reducing Viral Load Measurements to Once a Year in Patients on Stable, Virologically Suppressive Cart Regimen: Findings from the Australian HIV Observational Database
}

\author{
Mahshid Rafiee ${ }^{1}$, Azar Kariminia ${ }^{1}$, Stephen Wright ${ }^{1}$, Graham Mills ${ }^{2}$, lan Woolley ${ }^{3}$, Don Smith ${ }^{4}$, David J Templeton ${ }^{5}$, Matthew G Law ${ }^{1}$ and Kathy Petoumenos $^{1 *}$ \\ ${ }^{1}$ The Kirby Institute, UNSW Australia, Sydney, NSW, Australia \\ ${ }^{2}$ Department of Medicine, Waikato Hospital, Hamilton, New Zealand \\ ${ }^{3}$ Infectious Diseases Department, Monash Medical Centre, Vic., Australia; Department of Medicine, Monash University, Vic., Australia \\ ${ }^{4}$ The Albion Street Centre, Sydney, NSW, Australia; School of Public Health and Community Medicine, UNSW Australia, Sydney, NSW, Australia \\ ${ }^{5}$ The Kirby Institute, UNSW Australia, Sydney, NSW, Australia; RPA Sexual Health, Sydney Local Health District, Sydney, NSW, Australia; Central Clinical School, \\ University of Sydney, Sydney, NSW, Australia \\ *Corresponding author: Kathy Petoumenos, Senior Lecturer, Biostatistics and Databases Program, The Kirby Institute, Level 6, Wallace Wurth Building, UNSW \\ Australia, Sydney NSW 2052, Australia, Tel: (02)9385 0972; Fax: (02)9385 0940; E-mail: kpetoumenos@kirby.unsw.edu.au
}

Received date: October 16, 2014; Accepted date: November 19, 2014; Published date: November 25, 2014

Copyright: (C) 2014 Rafiee M, et al. This is an open-access article distributed under the terms of the Creative Commons Attribution License, which permits unrestricted use, distribution, and reproduction in any medium, provided the original author and source are credited.

\begin{abstract}
Reducing viral-load measurements to annual testing in virologically suppressed patients increases the estimated mean time those patients remain on a failing regimen by 6 months. This translates to an increase in the proportion of patients with at least one Thymidine Analogue Mutation from $10 \%$ to $32 \%$ over one year.
\end{abstract}

Keywords: HIV; Antiretroviral therapy; HIV viral load; HIV viral load monitoring; HIV resistance

\section{Introduction}

In the current era of effective treatment, reducing the frequency of virological monitoring may become more common. Current treatment guidelines recommend viral load monitoring every 3 to 4 months in clinically stable patients with suppressed viral load [1]. However, studies have previously indicated that viral load monitoring may be safely reduced to 6-monthly in stable patients [2]. There is little data on the impact of reducing viral load monitoring to annually, yet anecdotal evidence from Australia suggests that some clinicians are extending the interval between viral load measures for up to one year in clinically stable and virologically suppressed HIV positive (HIV+) patients.

We aimed to investigate the effects of reducing the frequency of viral load tests to annually among $\mathrm{HIV}^{\text {+ve }}$ patients with long-term virological control.

\section{Methods}

We used data from the Australian HIV Observational Database (AHOD). Patients were required to fulfil the following inclusion criteria: commenced combination Antiretroviral Therapy (cART) on or after 1 January 1997; remained virologically suppressed $(<400$ copies $/ \mathrm{mL}$ ) while on a stable cART regimen for at least one year; and had two or more viral load measurements per year.

Person-year methods were used to calculate the rate of virological failure (defined as two consecutive detectable viral loads $(\geq 400$ copies $/ \mathrm{mL}$ ) within one year or one measure of virological failure followed by a change of treatment within one year). Baseline date was the end of the first year of experiencing suppressed viral load while on a stable regimen. Follow-up was calculated from baseline to the time of virological failure; or (a) the date treatment was stopped/interrupted for more than 14 days or (b) the last visit date for patients who did not fail (censored).

To estimate the additional time a patient remained on a failing regimen if HIV viral load testing occurred annually we created a paired dataset by duplicating patient data and allowing each patient to act as his/her own control. The first line of data in each pair included all the viral load measures and the true stop or failure date from the observed data. The second line included a theoretical annual HIV test date calculated as the anniversary date of the baseline date. The patients' censor or failure date was therefore the last anniversary date from baseline that was greater or equal to the observed true stop or failure date. We calculated the additional time on a failing regimen as the time to failure using the observed data subtracted from the theoretical data.

We estimated the rate of accumulation of Nucleoside Reverse Transcriptase Inhibitor (NRTI), non- Nucleoside Reverse Transcriptase Inhibitor (NRTI) and Thymidine Analogue Mutation (TAM) resistance mutations if the rate of viral load testing was reduced to annual testing. Estimates were based on the rates of resistance accumulated in patients remaining on failing regimens as reported by Sigaloff et al. [3] and Cozzi-Lepri et al. [4]. We assumed the rate of resistance mutations accumulated exponentially and that virological failures occur uniformly in relation to viral load testing. Hence, if viral load testing was carried out annually, $25 \%$ of failures fail in the period 0-3 months after the previous viral load test, a further $25 \%$ in the period 3-6 months, $25 \%$ during 6-9 months and the final $25 \%$ during the period 9-12 months since the last viral load test.

To illustrate the absolute impact of reduced viral load testing we applied the failure rate reported in AHOD to a hypothetical population of $1000 \mathrm{HIV}$ patients who had been virologically 
Citation: Rafiee M, Kariminia A, Wright S, Mills G, Woolley I, et al. (2014) Reducing Viral Load Measurements to Once a Year in Patients on Stable, Virologically Suppressive Cart Regimen: Findings from the Australian HIV Observational Database . J AIDS Clin Res 5: 383. doi:10.4172/2155-6113.1000383

Page 2 of 3

suppressed on cART for one year, and subsequently followed for two years. We estimated the number of patients who would be expected to fail virologically based on AHOD data, the reduced number of viral load tests over the two years if only annual virological monitoring, and contrast that with the increase in proportion of failing patients who develop resistance during the two-year period.

\section{Results}

By March 2013, 3551 patients were recruited to AHOD, of whom 2651 started cART on or after 1 January 1997; 584 (16\%) patients fulfilled our study inclusion criteria. Most were male (92\%) with overall mean age of 50 years (SD: 11.2). The median viral load at cART initiation was 68200 copies/ml (IQR, 17 347-149 000).

Overall 76 patients (13\%) experienced virological failure over 1946 person-years (py) of follow-up with a failure rate of 3.9 per 100 py. Of the failures $64(84 \%)$ switched treatment following two consecutive failures while 12 patients (16\%) switched treatment after a single measurement of $>400$ copies $/ \mathrm{ml}$. The mean extra time patients remained on a failing regimen if viral load testing is reduced to annual was estimated at 6 months (SD: 3.1 ).

Table 1 shows the rate of accumulated resistance based on the rates reported by Sigaloff et al. [3] and Cozzi Lepri et al. [4]. If the frequency of viral load monitoring remained at every 3 months, then based on the Sigaloff data, we estimate that $10 \%$ would have TAM related resistance, while $4.4 \%$ would be NRTI-related and 7\% NNRTI-related. If viral load monitoring was performed annually and we assumed that of patients who failed $25 \%$ did so in each of the windows $0-3,3-6,6-9$ and 9-12 months following failure, then the estimated rate of resistance accumulated over one year would be $32 \%$ with at least one TAM, and $16 \%$ and $35 \%$ with any NRTI and NNRTI mutation respectively.

\begin{tabular}{|c|c|c|c|c|c|c|c|}
\hline \multirow[t]{2}{*}{ Studies } & \multirow[t]{2}{*}{ Mutation } & \multirow{2}{*}{$\begin{array}{l}\text { Rate of accumulation } \\
\text { (per month) } \\
(95 \% \mathrm{Cl})\end{array}$} & \multicolumn{5}{|c|}{${ }^{1}$ Probabilities of accumulated mutations } \\
\hline & & & $\begin{array}{l}0-3 \text { month } \\
\text { window }\end{array}$ & $\begin{array}{l}\text { 3-6 month } \\
\text { window }\end{array}$ & $\begin{array}{l}\text { 6-9 month } \\
\text { window }\end{array}$ & $\begin{array}{l}9-12 \text { month } \\
\text { window }\end{array}$ & $\begin{array}{l}\text { At one } \\
\text { year }\end{array}$ \\
\hline \multirow[t]{3}{*}{ Sigaloff et al. [3] } & $\mathrm{TAM}^{2}$ & $\begin{array}{l}0.07 \\
(0.04-0.11)\end{array}$ & 0.1 & 0.27 & 0.4 & 0.52 & 0.32 \\
\hline & NRTI-associated & $\begin{array}{l}0.03 \\
(0.01-0.06)\end{array}$ & 0.04 & 0.13 & 0.2 & 0.27 & 0.16 \\
\hline & $\begin{array}{l}\text { Any NNRTI } \\
\text { associated }\end{array}$ & $\begin{array}{l}0.05 \\
(0.03-0.09)\end{array}$ & 0.07 & 0.2 & 0.31 & 0.41 & 0.25 \\
\hline Cozzi-Lepri et al. [4] & Any TAM mutation & $0.02^{3}$ & 0.03 & 0.09 & 0.14 & 0.19 & 0.11 \\
\hline
\end{tabular}

Table 1: Probabilities of accumulated mutation for virological failure. ${ }^{1} \mathrm{We}$ assumed virological failure distributed uniformly during one year, $25 \%$ of failures fail in the period 0-3 months after the previous viral load test, a further $25 \%$ in the period 3-6 months, $25 \%$ during 6-9 months and the final $25 \%$ during the period 9-12 months since the last viral load test. ${ }^{2}$ Thymidine Analogue Mutation (TAM). ${ }^{3}$ Yearly rate was given in the Cozzi_Lepri, et al. study and therefore confidence interval for monthly rate cannot be calculated.

Based on the data from Cozzi-Lepri et al. [4] we estimated that with 3 -monthly viral load monitoring $3 \%$ of failing patients would have accumulated one or more TAMs, compared with an estimated $11 \%$ of failing patients with annual viral load monitoring.

In our hypothetical population of 1000 patients, if we applied the failure rate observed in AHOD (3.9/100 py) we estimate that 80 patients would have failed within two years. Regular three monthly viral load testing would yield approximately 9000 viral load tests over a complete 2-year period (including tests at baseline and at year 2). Reducing viral load testing to annually would reduce the viral load tests to 3000, a saving of around 6000 viral load tests over two years. However, based on the data from Sigaloff et al. [3] the reduction in viral load testing to annually would increase the rate of accumulated TAMs in the 80 patients who failed from $10 \%$ to $32 \%$.

\section{Discussion}

We reported a relatively high rate of virological failure of almost 4 per 100 py among virologically suppressed patients in AHOD. Reducing viral load testing to annually increased the time patients remained on a failing regimen for an additional 6 months. While this translates to 6000 less viral load tests over two years, the proportion of the 80 failures with at least one TAM could increase from $10 \%$ to $32 \%$ (applying the rates reported by Sigaloff et al. [3]); or from 3\% to $11 \%$ according to the Cozzi-Lepri estimates.

There is considerable variation in rates of developing antiretroviral resistance mutations in the published literature $[5,6]$. The lower estimate produced from the Cozzi-Lepri et al. [4] is based on patients from the EuroSIDA cohort and may more likely reflect the rates in other developed countries, including Australia. Although reducing viral load testing frequency may be cost-effective, as demonstrated in the case of reducing the frequency of CD4 monitoring [7], we have shown a high failure rate even among patients on apparently stable suppressive therapy. If viral load testing was reduced then around onethird of these patients who fail could potentially develop further resistance mutations, thereby reducing potential future treatment choices. Our results contrast with the findings by Reekie et al. who found that it is reasonable to extend visit intervals to 6 months for stable and fully suppressive patients on cART with minimal impact on treatment failure 3 to 6 months later [2].

There are some limitations to our analysis. First, we have used $>400$ copies for the virological failure cutoff as the data spanned over 10 years of data where many of the AHOD sites will still using assays at this level. However, using a higher viral load level in some ways may indicate true virological failures rather than virological blips that 
Citation: Rafiee M, Kariminia A, Wright S, Mills G, Woolley I, et al. (2014) Reducing Viral Load Measurements to Once a Year in Patients on Stable, Virologically Suppressive Cart Regimen: Findings from the Australian HIV Observational Database . J AIDS Clin Res 5: 383. doi:10.4172/2155-6113.1000383

Page 3 of 3

might range between 50 and 400 copies $/ \mathrm{mL}$. Second, we censored patients with treatment interruptions of greater than 14 days. We therefore would have excluded some patients who had one measure of virological failure and who stopped treatment, therefore still failing off treatment and subsequently accumulating resistance. Thirdly, we assumed that patients with virological failure were still taking some of their cART, thereby maintaining selection pressure for the evolution of resistance mutants. If these patients had discontinued all cART, ongoing viral evolution may not be occurring. Finally, we are unable to determine whether reducing the frequency of viral load testing would decrease the frequency of attendance or have an effect on adherence in this model.

Despite effective and well-tolerated regimens, stable and suppressed patients continue to fail therapy. While annual viral monitoring could reduce virological testing costs, our study suggests there could be a substantial increase in the numbers of failing patients who develop resistance which has its own costs due to more expensive resistance testing, treatment regimens and potential community costs of increased transmission of drug resistance virus. The pros and cons of reduced frequency of viral load monitoring in stable patients warrants more research, including well-conducted randomised trials.

\section{Acknowledgements}

Australian HIV Observational Database contributors: Asterisks indicate steering committee members in 2014.

New South Wales: D Ellis, General Medical Practice, Coffs Harbour; M Bloch, S Agrawal, T Vincent, Holdsworth House Medical Practice, Darlinghurst; D Allen, JL Little, Holden Street Clinic, Gosford; D Smith, R Hawkins, K Allardice, Lismore Sexual Health \& AIDS Services, Lismore; D Baker ${ }^{*}, \mathrm{~V}$ Ieroklis, East Sydney Doctors, Surry Hills; DJ Templeton*, CC O'Connor, S Phan, RPA Sexual Health Clinic, Camperdown; E Jackson, K McCallum, Blue Mountains Sexual Health and HIV Clinic, Katoomba; M Grotowski, S Taylor, Tamworth Sexual Health Service, Tamworth; D Cooper, A Carr, F Lee, K Hesse, St Vincent's Hospital, Darlinghurst; R Finlayson, S Gupta, Taylor Square Private Clinic, Darlinghurst; R Varma, J Shakeshaft, Nepean Sexual Health and HIV Clinic, Penrith; K Brown, V McGrath, S Halligan, N Arvela Illawarra Sexual Health Service, Warrawong; L Wray, R Foster, H Lu, Sydney Sexual Health Centre, Sydney; D Couldwell, Parramatta Sexual Health Clinic; DE Smith ${ }^{*}$ V Furner Albion Street Centre; Clinic 16 - Royal North Shore Hospital, S Fernando; Dubbo Sexual Health Centre, Dubbo; J Watson*, National Association of People living with HIV/AIDS; C Lawrence*, National Aboriginal Community Controlled Health Organisation; B Mulhall ${ }^{*}$, Department of Public Health and Community Medicine, University of Sydney; M Law ${ }^{*}$, K Petoumenos $^{*}$, S Wright ${ }^{*}$, H McManus ${ }^{*}$, C Bendall ${ }^{*}$, M Boyd ${ }^{*}$, The Kirby Institute, University of NSW. Northern Territory: N Ryder, R Payne, Communicable Disease Centre, Royal Darwin Hospital, Darwin. Queensland: M O'Sullivan, S White, Gold Coast Sexual Health Clinic, Miami; D Russell, S Doyle-Adams, C Cashman, Cairns Sexual Health Service, Cairns; D Sowden, K Taing, K McGill, Clinic 87, Sunshine Coast-Wide Bay Health Service District, Nambour; D Orth, D Youds, Gladstone Road Medical Centre,
Highgate Hill; M Kelly, D Rowling, N Latch, Brisbane Sexual Health and HIV Service, Brisbane; B Dickson ${ }^{*}$, CaraData. South Australia: W Donohue, O'Brien Street General Practice, Adelaide. Victoria: R Moore, S Edwards, R Woolstencroft Northside Clinic, North Fitzroy; NJ Roth*, H Lau, Prahran Market Clinic, South Yarra; T Read, J Silvers*, W Zeng, Melbourne Sexual Health Centre, Melbourne; J Hoy ${ }^{*}, \mathrm{~K}$ Watson ${ }^{*}, \mathrm{M}$ Bryant, S Price, The Alfred Hospital, Melbourne; I Woolley, M Giles ${ }^{*}, \mathrm{~T}$ Korman, J Williams ${ }^{*}$, Monash Medical Centre, Clayton. Western Australia: D Nolan, J Robinson, Department of Clinical Immunology, Royal Perth Hospital, Perth. New Zealand: G Mills, C Wharry, Waikato District Hospital Hamilton; N Raymond, K Bargh, Wellington Hospital, Wellington.

\section{Funding Source}

The Australian HIV Observational Database is funded as part of the Asia Pacific HIV Observational Database, a program of The Foundation for AIDS Research, amfAR, and is supported in part by a grant from the U.S. National Institutes of Health's National Institute of Allergy and Infectious Diseases (NIAID) (Grant No. U01-AI069907) and by unconditional grants from Merck Sharp \& Dohme; Gilead Sciences; Bristol-Myers Squibb; Boehringer Ingelheim; Janssen-Cilag; ViiV Healthcare. The Kirby Institute is funded by the Australian Government Department of Health and Ageing, and is affiliated with the Faculty of Medicine, UNSW Australia. The views expressed in this publication do not necessarily represent the position of the Australian Government.

\section{References}

1. Aidsinfo (2014) Laboratory Testing Plasma HIV-1 RNA (Viral Load) and CD4 Count Monitoring.

2. Reekie J, Mocroft A, Sambatakou H, Machala L, Chiesi A, et al. (2008) Does less frequent routine monitoring of patients on a stable, fully suppressed cART regimen lead to an increased risk of treatment failure? AIDS 22: 2381-2390.

3. Sigaloff KC, Ramatsebe T, Viana R, de Wit TF, Wallis CL, et al. (2012) Accumulation of HIV drug resistance mutations in patients failing firstline antiretroviral treatment in South Africa. AIDS Res Hum Retroviruses 28: $171-175$.

4. Cozzi-Lepri A, Phillips AN, Martinez-Picado J, Monforte Ad, Katlama C, et al. (2009) Rate of accumulation of thymidine analogue mutations in patients continuing to receive virologically failing regimens containing zidovudine or stavudine: implications for antiretroviral therapy programs in resource-limited settings. J Infect Dis 200: 687-697.

5. Marconi VC, Sunpath H, Lu Z, Gordon M, Koranteng-Apeagyei K, et al. (2008) Prevalence of HIV-1 drug resistance after failure of a first highly active antiretroviral therapy regimen in KwaZulu Natal, South Africa. Clin Infect Dis 46: 1589-1597.

6. Barth RE, Aitken SC, Tempelman H, Geelen SP, van Bussel EM, et al. (2012) Accumulation of drug resistance and loss of therapeutic options precede commonly used criteria for treatment failure in HIV-1 subtypeC-infected patients. Antivir Ther 17: 377-386.

7. Hyle EP, Sax PE, Walensky RP (2013) Potential savings by reduced CD4 monitoring in stable patients with HIV receiving antiretroviral therapy. JAMA Intern Med 173: 1746-1748. 